\title{
ALMEIDA JÚNIOR: UM CAIPIRA ILUMINADO
}

Kátia Maria Furtado de Mendonça Curtis

Resumo: O presente artigo pretende evidenciar a modernidade de José Ferraz de Almeida Júnior, na segunda metade do século XIX, no panorama artístico brasileiro. Este trabalho tem a finalidade de destacar os aspectos inovadores da obra desse artista que apesar de conhecer, em Paris, os românticos, realistas e impressionistas, não se filiou a nenhuma corrente; que, mesmo respirando os ares inquietos da arte europeia, permaneceu sereno no trato da sua paleta; que, tendo olhado para a luminosidade dos impressionistas, conseguiu encontrar o seu próprio sol; que tendo convivido com a sofisticação do primeiro mundo, permaneceu brasileiro e caipira, tornando-se precursor de uma pintura genuinamente brasileira. $\mathrm{O}$ artista que alicerçou sua obra em fundo humano e observou tantas tendências, anunciou a modernidade artística do nosso país com seus temas, luzes e cores. Transportou para suas telas a realidade rústica e pitoresca de sua terra e a dignidade de sua gente.

Palavras-Chave: caipira, luminosidade, tema regional, realidade, modernidade.

Abstract: This article is meant to evince the modernism of José Ferraz de Almeida Júnior, during the second half of the XIX century, in the Brazilian artistic scenery. This work has the objective of highlighting the innovative aspects of the creation of this artist that despite having contacted in Paris the romantics, realists and impressionists, didn't join any course; that even breathing the restless airs of the European arts, remained placid in the treatment of his palette; that having looked at the luminosity of the impressionists, was able to find his own sun; that despite the sophistication of the first world, remained Brazilian and peasant, becoming the pioneer of a genuine Brazilian painting. The artist that founded his work on a humanistic base and observed so many tendencies announces the artistic modernism of our country with his themes, lights and colors. Transferred to his paintings the rustic and colorful reality of his native land and the dignity of its people.

\footnotetext{
.* Mestra em História Social pela Universidade de São Paulo (USP); Licenciada em História pela Universidade Federal do Rio Grande do Norte (UFRN); Professora de História da Arte e de História Moderna do Centro Universitário Assunção (UNIFAI), São Paulo.
} 
Keywords: peasant, luminosity, regional themes, reality, modernity.

Almeida Júnior, detentor de uma legítima vocação artística e de um talento raro, nasceu no dia 8 de maio de 1850, em Itu, pequena cidade paulista que, naquela época, era habitada por gente patriarcal, sempre ocupada com as questões de terra e que, dificilmente, poderia despertar pendores artísticos em quem não tivesse inclinações naturais para o nobre mister. Filho de Ana Cândida de Amaral Sousa e de José Ferraz de Almeida (de quem teria herdado o gosto pela pintura), Almeida Júnior passou a infância em um ambiente familiar simples, pacato, temperado com afeto e carinho. Pouco sabemos de seus primeiros anos e adolescência, mas encontramos referências à precocidade de seu amor pelo desenho e pelas cores (Lourenço In: Almeida, 2007).

Muito cedo começou pintando retratos e temas religiosos para complementar o orçamento familiar. Em 1869, graças à iniciativa do Padre Miguel Correa Pacheco, pároco de Itu, que teve a ideia de coletar dinheiro entre os fiéis para ajudar o jovem artista, Almeida Júnior segue para o Rio de Janeiro com a finalidade de estudar na Academia Imperial de Belas Artes. Lá, na capital do país, em 1869, aluno da tradicional instituição, seu carregado sotaque caipira, linguajar matuto e as roupas simples que sempre usara na província parecem ter motivado gracejos e galhofas daquela elite acadêmica, conduta que hoje classificaríamos como bullying. Mas nada impediu que o aluno caipira, aprendiz de Victor Meireles e Julio Le Chevrel, se destacasse e exibisse um talento precioso, recebendo prêmios, inclusive a grande medalha de ouro pela obra Ressurreição do Senhor. Tal desempenho qualificava o ituano para concorrer ao prêmio de viagem à Europa, mas preferiu voltar a sua cidade, onde inaugurou um ateliê, dedicando-se a pintar retratos e ministrar aulas de desenho.

D. Pedro II, que já havia admirado as obras do melhor aluno da Academia, surpreendeu-se quando, em visita a Itu para inaugurar a Estrada de Ferro Mogiana, ao encontrá-lo na província. Pensava o Imperador que o talentoso pintor havia pleiteado o aprendizado na Europa, como fizera jus ao ser premiado com a maior condecoração da meca do ensino artístico no Brasil. Novamente impressiona-se com a maestria de Almeida Júnior que expunha, naquela ocasião, algumas obras. Um retrato destacava-se de forma especial, aquele de Antônio Gueiros Teles, futuro Visconde de Parnaíba, pintura que evidenciou, de forma inequívoca, as virtudes artísticas do retratista. Assim, o Imperador mecenas não hesitou em financiar, com seus próprios recursos, o aperfeiçoamento do ituano na Europa. 
Por um decreto da Mordomia da Casa Imperial, em 1876, o nosso pintor passa a receber uma bolsa de 300 francos mensais e, no mesmo ano, no dia 04 de dezembro, já está matriculado na Escola Superior de Belas Artes de Paris, tornando-se discípulo de Alexandre Cabanel (1823 1889), famoso artista da época.

Almeida Júnior expõe em vários Salons de Paris: em 1879 com a obra Retrato de Dr. José de Magalhães; em 1880 com Remorso de Judas e O Derrubador Brasileiro; em 1881 com a tela Fuga para o Egito e, em 1882, com Descanso de Modelo.

Após receber elogios da crítica parisiense, retorna ao Brasil em 1882, e expõe na Academia Imperial os trabalhos realizados em Paris. Nessa ocasião, presenteia o Imperador com a obra Fuga para o Egito, como registro da sua gratidão, presente esse que, posteriormente, D. Pedro II doou à Academia Imperial de Belas Artes, hoje Museu Nacional de Belas Artes.

A corte não seduz o grande artista que regressou a Itu e, depois, em 1883, instala seu ateliê em São Paulo. Fica indiferente quando é indicado, por unanimidade, para o cargo de professor honorário da Academia, permanecendo com suas tintas, pincéis e telas, exercendo o seu ofício, enobrecendo o nosso universo artístico, anunciando, com arautos coloridos e silenciosos, uma pintura genuinamente brasileira. $O$ executor de retratos primorosos trabalhou para a nova ascendente elite paulista, alicerçada nas atividades cafeeiras e que se dividia entre o interior e a capital, São Paulo, que se agigantava com a chegada dos imigrantes e a riqueza advinda do café. $\mathrm{O}$ pintor de personagens destacados da monarquia, afirmou-se também retratando seguidores e baluartes da República.

$\mathrm{O}$ artista de vida simples, descrito por muitos como "caipira", foi um pintor que soube dialogar com os movimentos artísticos do seu tempo, absorvendo o que cabia em sua arte e contribuía para o seu sonho de representar, em suas telas, a dignidade de sua gente e a realidade de sua terra (Dias, 2013). As suas fontes propiciaram a construção de uma obra autêntica, genuína, abrigando um repertório variado, porém sempre carregado de força técnica e lucidez intelectual.

Notamos, na obra de Almeida Júnior, influências dos realistas Gustave Courbet (1819 1877), Édouard Manet (1832 - 1883) e, também, de Jean-François Millet (1814 - 1875), artista que será sempre lembrado por retratar trabalhadores rurais na sua lida. Percebemos, ainda, em algumas obras, a pincelada densa, volumosa que certamente foi inspirada em Paul Cézanne (1839 - 1906). Mas, realmente, o que nos provoca admiração maior é sua independência artística, evidente quando consegue romper com muitos dos cânones neoclássicos, dialogar com o realismo e o impressionismo e, com primorosa técnica, trilhar o seu próprio caminho. 
O ituano superou as imposições da crítica contemporânea tradicional e conseguiu fazer-se respeitar por aqueles que, depois, viriam a mudar os rumos da Arte Brasileira.

Mário de Andrade, um dos artífices da nossa modernidade artística, no seu estudo sobre o Aleijadinho, faz o seguinte comentário: "De fato, Antonio Francisco Lisboa profetizava para a nacionalidade um gênio plástico que os Almeida Júnior posteriores, tão raros, são insuficientes para confirmar" (in Grandes Artistas Brasileiros - Almeida Júnior, 1985:10). Notamos, nessa afirmativa do grande intelectual brasileiro, o reconhecimento da importância da obra do nosso pintor caipira, lamentando a ausência de mais talentos similares que pudessem enriquecer o nosso panorama artístico.

Luis Martins tem a seguinte visão da obra do autor de Caipira picando fumo:

A importância social da obra de Almeida Júnior é significativa. Ele é o pintor da madrugada do nosso fastígio agrícola, o fixador da nossa vida rural no início da era da grandeza do café. Ele traduzia todas as esperanças, todas as ilusões e todas as hipóteses de magnificência de um século que ia nascer sob o maior otimismo de todos (in Grandes Artistas Brasileiros - Almeida Júnior, 1985, p.10).

A primazia de nossa riqueza agrária fora transferida de Pernambuco para São Paulo, decorrência da depauperação da lavoura do açúcar e o progresso faustoso das plantações de café, o “ouro verde”, como era chamado no início do século passado. Almeida Júnior vai registrar, entre outros temas do seu vasto repertório, o ambiente dessa nova realidade econômica e social brasileira, destacando o tipo humano sofrido que iria alicerçar a grande riqueza paulista, nas primeiras décadas do século XX.

O humilde caipira que Monteiro Lobato popularizou na personagem de Jeca Tatu foi pintado em tantas telas, com tantas cores, detalhes e luzes, pelo talentoso artista paulista. Em cada obra demonstra afetividade pela sua gente e pelo seu rincão enobrecendo, com o seu pincel primoroso, o universo interiorano.

No olhar de Gilda Mello e Souza:

Não é possível entender bem a pintura brasileira anterior ao modernismo sem uma referência à sua atuação, que ajudou a suprimir a monumentalidade das obras, a renovar os assuntos e as personagens, a vincular organicamente as figuras ao ambiente e talvez reformular o tratamento da luz. É com ele que ingressa pela primeira vez na pintura o homem brasileiro (SOUZA, In: DIAS, 2007, p. 19). 
Alguns críticos costumam dividir a obra do ituano em duas fases distintas: a primeira dedicada a temas narrativos e religiosos, enquanto a segunda caracteriza-se por ter os olhos voltados para os cenários e os tipos caipiras, quando, também, a paleta ficou mais clara e ornada com outras cores e novos recursos luminosos. Na realidade, independentemente das mudanças técnicas, essa divisão é questionável, uma vez que obras como O Derrubador Brasileiro, de 1879, e O Importuno, de 1898, estariam deslocadas nessa divisão. O Derrubador Brasileiro já ingressara na temática caipira e no uso de pinceladas largas e luminosas, portanto destoando do panorama da chamada primeira fase, enquanto $O$ Importuno retomou o gênero narrativo que não estaria inserido na segunda fase (Cardoso, 2008).

Diante dessas colocações pretendemos deixar de lado essa divisão contraditória e continuar discorrendo sobre o que nos parece realmente importante: a modernidade de Almeida Junior na segunda metade do século XIX.

Na visão de Oswald de Andrade: “Almeida Júnior foi precursor, encaminhador e modelo de uma pintura nacional.” (In: Cardoso, 2008, p. 119). Essa declaração de 1915, de um dos pais do nosso modernismo, vem corroborar a nossa afirmativa, lembrando que além de uma nova temática, o ituano introduziu no cenário pictórico brasileiro uma luz especial, luz esta que soube manipular com sensibilidade e rara competência. Ele fez do sol o grande agente de sua atmosfera, sol que aquecia a terra e queimava a pele de seus amados caipiras.

A luz, na obra de Almeida Júnior, sempre despertou discussões e grandes polêmicas entre os críticos, principalmente no que se refere à relação entre sua luz e o impressionismo. Aracy Amaral observa que, na visão de Ligia Martins Costa, o ituano avançara mais que qualquer outro seu contemporâneo, apresentando na obra Fuga da Sacra Família para o Egito (1881) toques impressionistas evidentes, que teriam desaparecido no seu retorno ao Brasil (Amaral, In: Almeida, 2007).

Segundo Gilda de Mello e Souza (2007), o impressionismo teria tocado indiretamente Almeida Júnior que incorporou às suas telas as cores vivas despertadas pelo sol. Para Lourival Gomes Machado, Almeida Júnior permaneceu sempre um acadêmico. Mário de Andrade, em uma carta, fala que as obras do nosso paulista "eram berrantemente coloridas e emancipadas das suaves transições de sombras" (Amaral In: Almeida, 2007: 239). Analisando as diversas críticas e superando todas as divergências, Aracy Amaral, com grande propriedade, capta a essência da obra do ituano: 
E por que desejar que Almeida Júnior fizesse o mesmo percurso dos impressionistas da Escola de Paris? Por que considerar uma regressão ou cristalização de sua trajetória as telas que produziria a seu regresso da Europa, somente porque se dedicaria, a par de suas encomendas, a uma temática que, longe do usual, exemplificaria sua autonomia de vôo em um meio novo que acolhe sua produção? Como só ver sentimentalismo e empatia com seu entorno e não reconhecer que essa motivação a tornou original como obra? Não importa que outros tenham vindo depois, imitando-o com mediocridade em academia regionalista. Almeida Júnior permanece sensível à luz, à luz local, manipulando-a com rara maestria ao tirar dela partido do ponto de vista formal. Daí porque a poética de sombras como "Saudade", "Leitura" e "Cozinha Caipira" destaca uma peculiar apropriação do valor da "luz", distanciada das preocupações impressionistas. Mas também parece projetar visualmente uma deglutição do impressionismo a partir da cultura e da sensibilidade brasileiras de um tempo de que Almeida Júnior foi, sem dúvida, o porta voz mais expressivo. (Amaral In: Almeida, 2007, p. 244)

Vale lembrar que o clareamento da paleta e a utilização da luz brasileira não o fizeram negligenciar a precisão do desenho e o realismo na anatomia. Jamais abandonou os ensinamentos dos seus professores e as referências apreciadas nos contatos com diversos artistas. Mas, o seu grande mérito reside no fato de ter encontrado o seu próprio caminho, de ter sabido pintar com maestria os vários temas que visitou, de ter lidado de forma precisa com as cores, captando suas nuances e vibrações. Uma característica sempre encontrada na pintura de Almeida Júnior, presente tanto nas primeiras telas quanto nas derradeiras, é o sentido firme e exato da composição, que apresenta uma estabilidade indispensável às suas concepções artísticas.

Almeida Júnior passou para suas telas vários gêneros, sendo o retrato um dos mais requisitados e aquele que garantiu o seu sustento em muitas ocasiões. Mas a paleta do ituano ocupou-se também de temas religiosos e históricos, paisagens, naturezas mortas, cenas de interiores artísticos e domésticos, mulheres leitoras e, acima de tudo, as suas cenas regionais que apresentam para o mundo o nosso caipira, a sua lida, seus costumes, sua grandeza.

Não poderíamos deixar de analisar algumas das obras que evidenciam a modernidade e a excelência da arte desse artista que iniciou a construção de uma pintura genuinamente brasileira. 


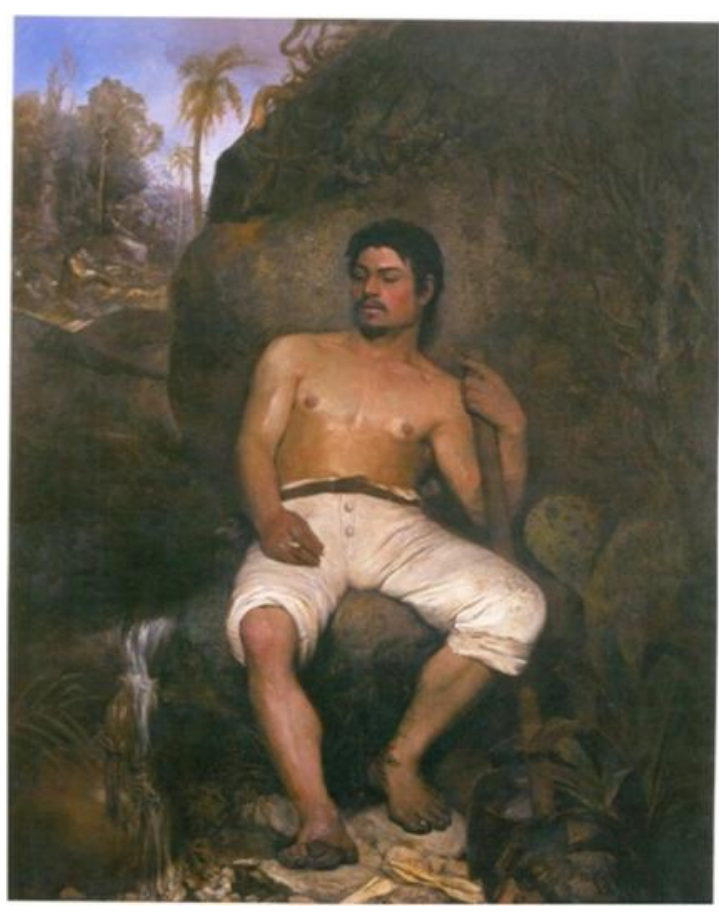

O Derrubador Brasileiro - 1879 (Almeida, 2007)

O Derrubador Brasileiro, obra de 1879, joia primorosa do Museu Nacional de Belas Artes, tem que iniciar o elenco de telas que serão comentadas. Essa pintura nos apresenta um homem sem camisa tendo ao lado um machado, instrumento da sua lida, em repouso e apoiado em seu braço esquerdo. O momento retratado é o da pausa necessária após o esforço exaustivo. No início, o tema foi identificado como o retrato da preguiça, mas qualquer bom observador reconhece o empenho do autor em mostrar o trabalhador exausto, descansando em meio à paisagem, fumando um cigarro, exibindo músculos que resultam da atividade extenuante de derrubada da mata. $\mathrm{O}$ pintor joga com a alternância entre trabalho e repouso, valorizando a rotina e denunciando a luta do homem para sobreviver. O derrubador fatigado surge destacado e enobrecido uma vez que é o foco luminoso da tela, realçado pela massa escura que o cerca (Lourenço, In: Almeida, 2007). 


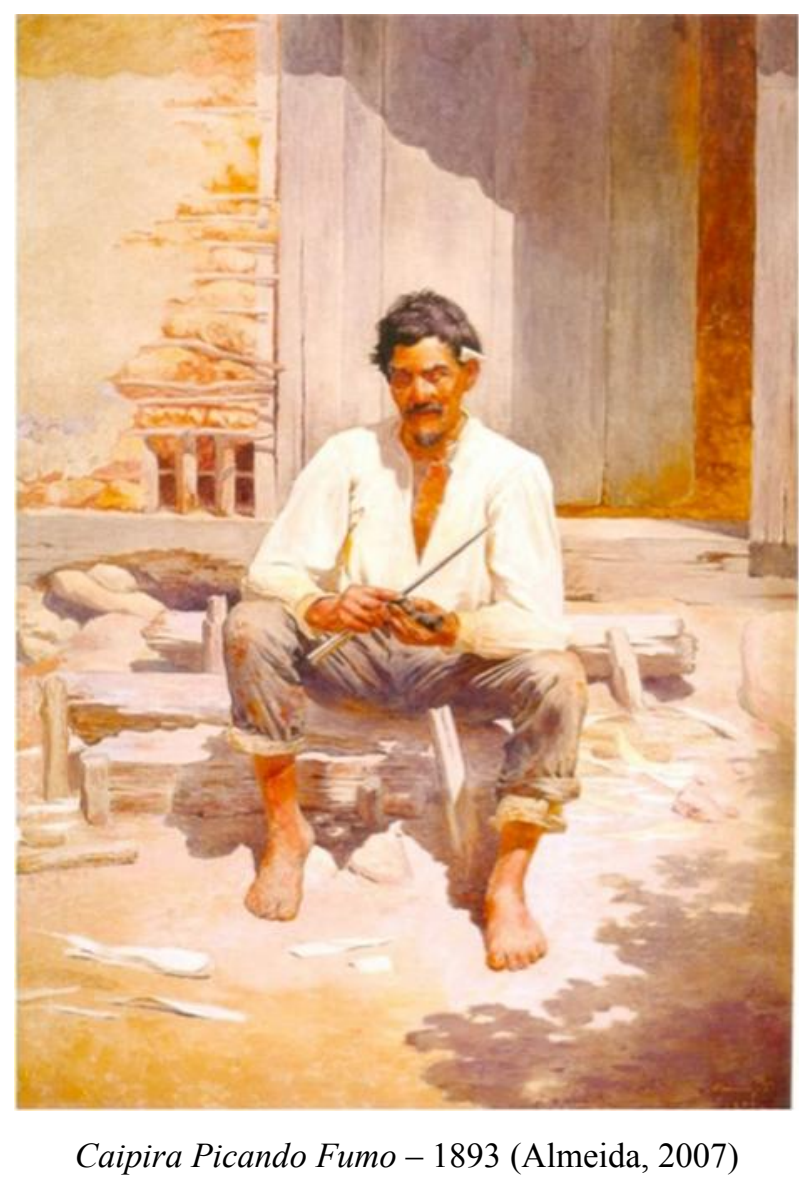

Em Caipira Picando Fumo (1893), obra do acervo da Pinacoteca, Almeida Júnior retrata o homem simples, sem horizontes, dedicado à tarefa prosaica do preparo do cigarro de palha, cortando o fumo com um enorme facão. Dedica-se à tarefa sem pressa ou preocupações. Novamente o caipira é surpreendido em um momento de descanso, a pausa merecida após a conclusão dos afazeres cotidianos. O tema, aparentemente sem importância, é apresentado com rara maestria tanto na composição rigorosa, quanto no uso da luz. O caipira, com a pele queimada pelo sol causticante, é colocado no centro da composição, destacado por uma camisa branca, banhado por uma luz aplicada com um pincel competente. Portanto, o caboclo, mesmo sentado no chão em frente a um paiol de paredes de pau a pique, apresenta-se imponente, grandioso. 


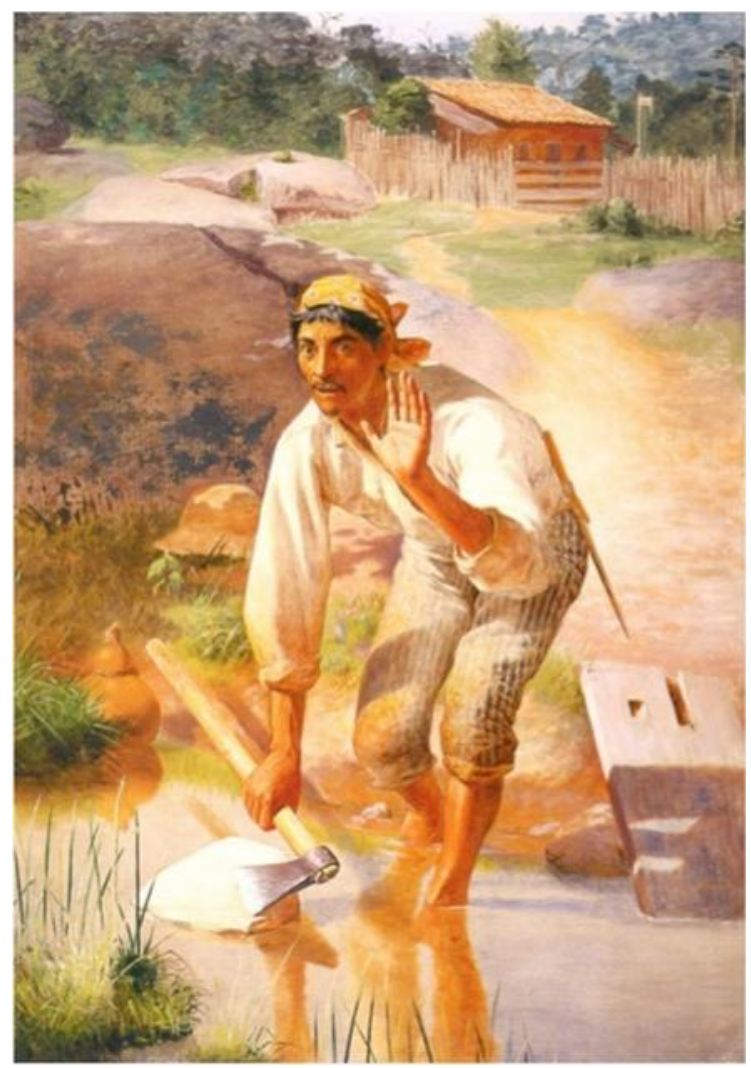

Amolação Interrompida - 1894 (Almeida, 2007)

$\mathrm{Na}$ tela Amolação Interrompida (1894), também da Pinacoteca, o homem do campo novamente é surpreendido em meio a uma ocupação cotidiana e, mais uma vez, Almeida Júnior põe de lado as idealizações consagradas pela Academia. O caboclo, com o rosto vincado pelo tempo, outra vez vestido com camisa branca e banhado de luz, interrompe a sua tarefa de amolar o machado em uma pedra, dentro de um riacho, para acenar em direção a alguém, não nos fitando diretamente, excluindo, portanto, o expectador da ação. O pintor deixa em aberto vários questionamentos, aguçando a nossa curiosidade sobre quem estaria interrompendo a tarefa e a respeito das finalidades de tal interferência. Por meio de um desenho impecável e de luzes e cores aplicadas com maestria, o ituano, mais uma vez, documenta o trabalhador dignificando o seu ofício. Usa cromatismo precioso, aplica texturas bem elaboradas e capta uma expressão humana peculiar (Dias, 2013). 


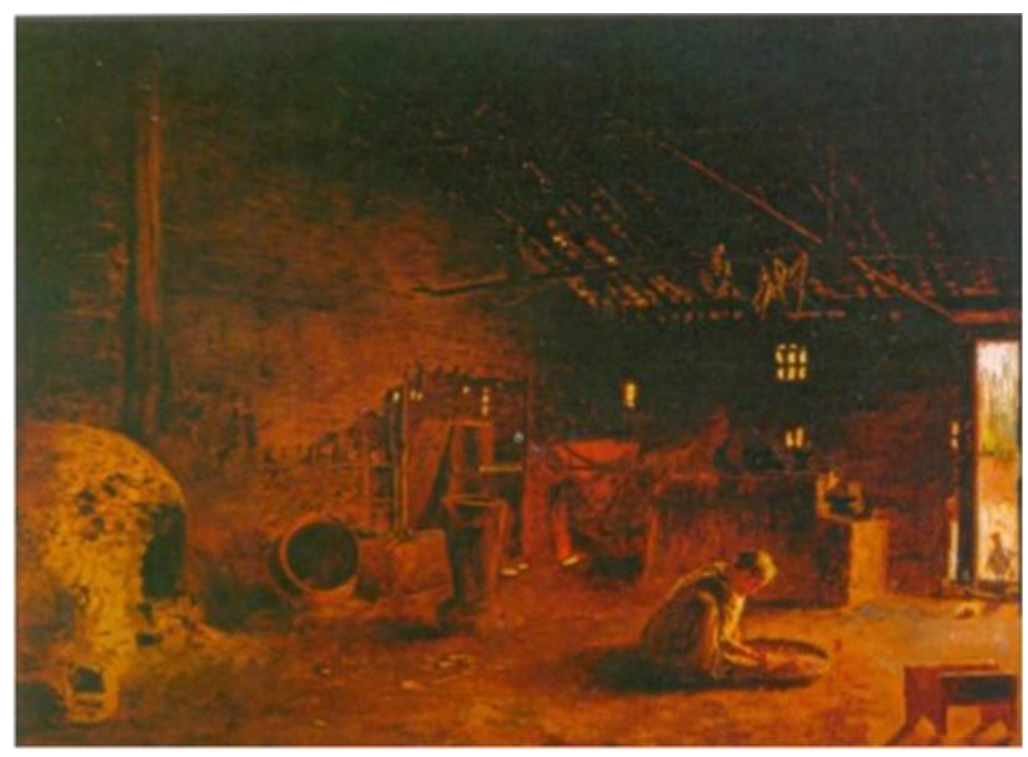

Cozinha Caipira - 1895 (Almeida, 2007)

Em Cozinha Caipira (1895), mais uma joia da Pinacoteca, Almeida Júnior com seu pincel generoso e competente retrata, com afeto, uma cozinha da roça com fogão e forno de lenha, carnes e linguiça em varal de defumação, palhas de milho secando, panela de ferro, pilão, tachos e parede ripada. Esse universo singelo da cozinheira caipira é pintado em tons marrons e castanhos, com a luz penetrando suavemente pela porta e por uma pequena janela à direita, iluminando os objetos dispersos pelo espaço humilde e característico de moradias rurais. A luz destaca o contorno de uma mulher que trabalha agachada, vestida modestamente, escolhendo grãos em uma peneira. Novamente o ituano exalta, com a sua luz, a lida de sua gente. A maneira como o pintor registrou esse tema denota certa influência das obras do artista francês Jean-Baptiste Siméen Chardin (16991779) que dedicou muitas das suas telas à vida doméstica e aos interiores suavemente iluminados, inspirado, certamente, em alguns pintores holandeses. Porém, a cena descrita por Almeida Júnior vem carregada de afeto e de características que o individualizam na História da Pintura Brasileira. 


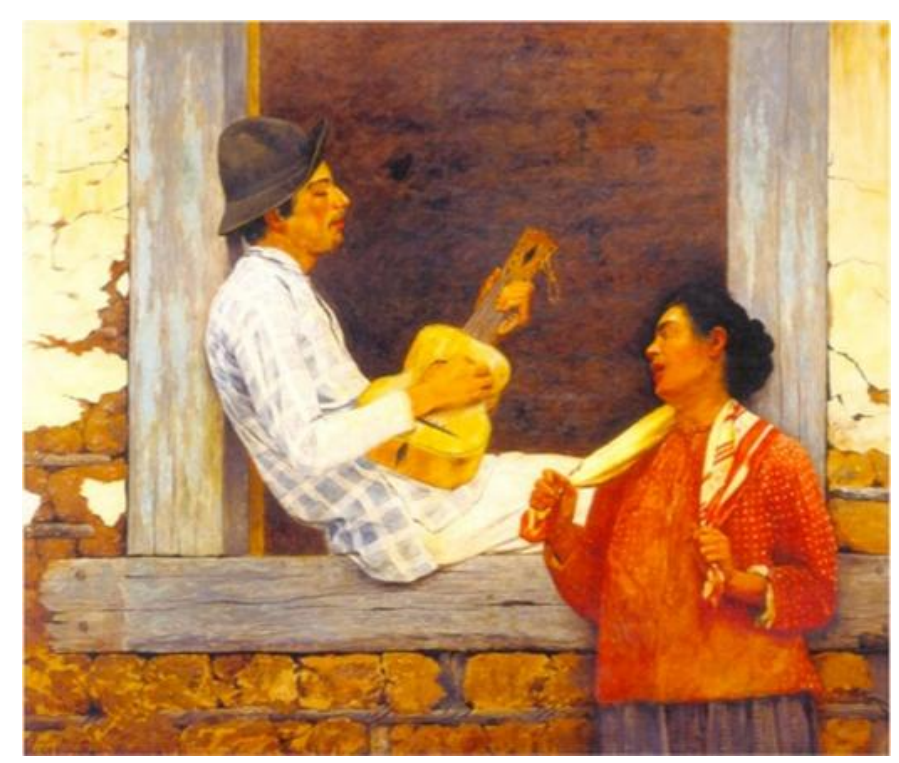

O Violeiro - 1899 (Almeida, 2007)

Na tela $O$ Violeiro, de 1899, que faz parte do acervo da Pinacoteca, o ituano registra o prazer simples e congregador do cotidiano caipira. O tema é pintado com um colorido harmonioso e exato, submetido a uma posição calculada com rigor, onde as duas personagens são emolduradas por uma janela, estando o violeiro em diagonal e a cantora em vertical, apresentando detalhes característicos daqueles momentos de lazer. O rigor geométrico do artista mais uma vez é demonstrado e a cena denuncia, com grande realismo, a simplicidade dos retratados vestidos com tecidos simples e entregues à musica, escorados em moldura de madeiras rachadas e paredes de pau a pique com o reboco descascado. Eles não se olham, nem tampouco fitam o espectador, estão absorvidos pelo prazer dos sons da viola e da canção que está sendo interpretada. É mais um registro primoroso do seu universo rural. 


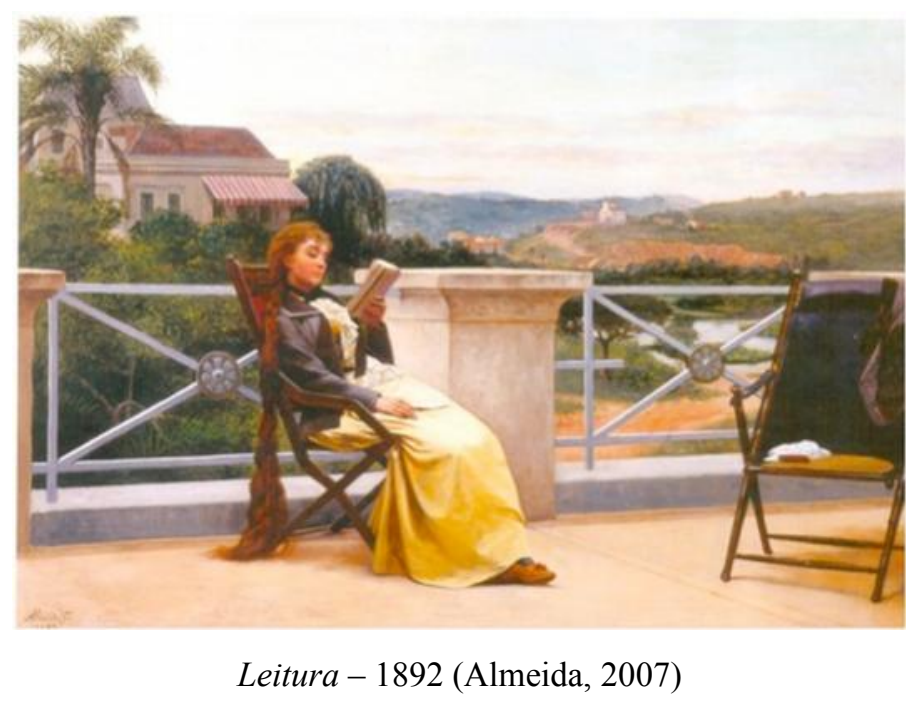

Em Leitura (1892), tela da Pinacoteca, o pintor retrata uma mulher dedicada ao prazer da leitura, tema recorrente na obra de Almeida Júnior. Uma moça bem vestida, sentada com displicência em uma cadeira na varanda de uma casa requintada, com detalhes que denunciam a cuidadosa educação da personagem. A modelo é muito parecida com Rita Ybarra, com quem o ituano manteve um relacionamento, ligação que gerou um filho, Mário Ybarra de Almeida (1893 1952), seu único herdeiro. A liberdade da composição e da perspectiva e os recursos luminosos leves e retinianos atestam as influências que o impressionismo exerceu sobre Almeida Júnior. Ao lado da jovem culta, uma cadeira vazia com uma capa e alguns objetos denunciam a ausência de alguém que deveria estar presente. Quem sabe o pintor quisesse registrar o fato de que ali não estava o amante que jamais oficializou o matrimônio com Rita Ybarra. Estaria o autor fazendo uma referência a sua situação amorosa? 


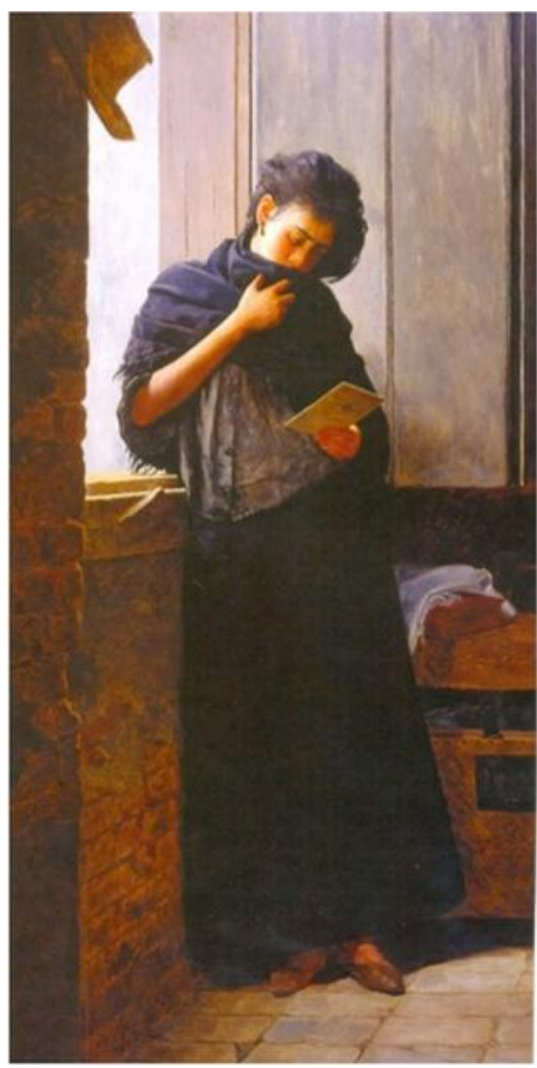

Saudade - 1899 (Almeida, 2007)

A obra Saudade (1899), também componente do inestimável acervo da Pinacoteca, é uma das telas mais intrigantes do ituano. Notamos nela, além do talento precioso do autor, aspectos que denunciam um caráter biográfico e, quem sabe, premonitório. $\mathrm{O}$ ano no qual a tela foi pintada é também o da morte violenta do artista que, com a sua partida, deixou inconsolável o grande amor de sua vida: Maria Laura do Amaral Gurgel, sua prima e amante. Na pintura, uma jovem viúva enlutada fita, consternada, uma fotografia. Com um xale, sufoca os soluços provocados pela saudade dolorosa e é cercada por um ambiente simples e de cromatismo escuro, reduzido a preto, marrom e cinza. Um chapéu pendurado na parede atesta a ausência de alguém que é a causa de tanto sofrimento. Novamente o ituano nos apresenta um ambiente iluminado por uma janela aberta, dominado por uma ordenação geométrica regular nos elementos constitutivos da casa, contrastando com os tijolos desgastados pelo tempo e, portanto, irregulares, evidenciando um horizonte sem perspectivas. Tal cenário desperta a lembrança das obras de Johannes Vermeer (1632-1675), o mestre da luz, pintor holandês que privilegiou temas do cotidiano com personagens banhados de luz, elementos de composições equilibradas e coesas. Mas, novamente, percebemos 
que Almeida Júnior soube tratar as informações recebidas sem abandonar o seu caminho, o seu próprio repertório de técnicas e a sua brasilidade.

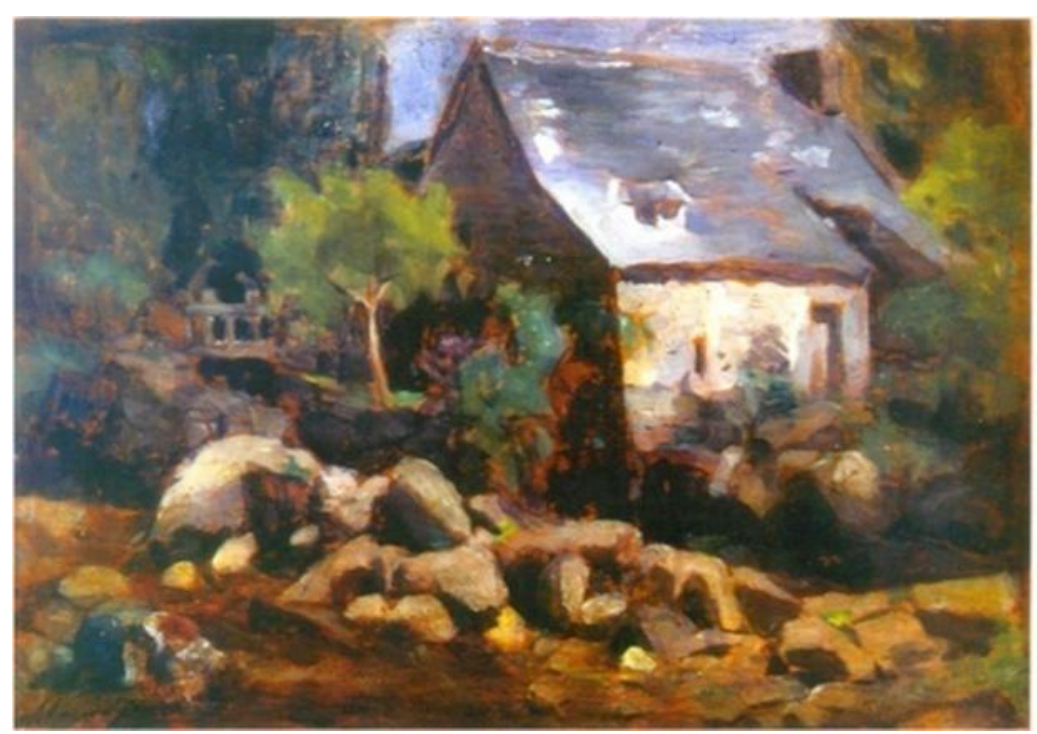

Paisagem Rústica com Ponte e Casas - s/d (Almeida, 2007)

Em Paisagem rústica com ponte e casas (s/d), obra do acervo do Museu de Arte de São Paulo (MASP), o artista pinta um cenário rústico, tratado com deferência, onde expõe seu modernismo na representação da natureza. Suas formas e o colorido lembram Paul Cézanne, pois simplifica os elementos e aplica grossas pinceladas. No trato da vegetação ao fundo e nas árvores que aparecem no segundo plano, o artista evidencia sua maestria revolucionária no competente emprego da luz e nas pinceladas espessas e fracionadas.

Em outras paisagens como Casa Rústica (1897), Paisagem Fluvial (1899) e Paisagem do sítio do Rio das Pedras (1899) fica visível a fascinação do pintor pela natureza, a facilidade com que usa manchas coloridas, pinceladas fracionadas, contrastes entre as cores complementares e uma surpreendente luminosidade.

Quando visitamos essas obras de Almeida Júnior, temos a certeza de que se vivo estivesse em 1922, estaria na linha de frente do movimento que libertou a nossa arte dos cânones impostos pelos conservadores neoclássicos.

No dia 13 de novembro de 1899, aos 49 anos de idade, José Ferraz de Almeida Júnior morreu apunhalado em Piracicaba por José de Almeida Sampaio, marido de sua amante Maria Laura Amaral Gurgel, o grande amor de sua vida. 
Morreu, assim, o nobre caipira, o paulista que anunciou a modernidade artística do nosso país, que trouxe para o centro do nosso universo pictórico o caipira sofrido, lutador, corajoso. Morreu, de forma trágica, o artista que pintou um vasto repertório de temas, iluminados por uma luz especial, construídos com maestria e sensibilidade. Desapareceu, naquele dia de novembro, o precursor de uma pintura verdadeiramente brasileira.

Entre as muitas notícias veiculadas na imprensa brasileira, por ocasião de seu falecimento destaca-se, de modo especial, um texto escrito por Arthur Azevedo no jornal "O Paíz" do Rio de Janeiro, de 15 de novembro de 1899, que define com rara propriedade o prejuízo que o desaparecimento de Almeida Júnior provocará na arte do nosso país:

(...) Pobre Almeida Júnior! Quem adivinharia que ele morreria dessa morte de aventureiro, ele, tão tímido, tão modesto, com aqueles doces ares campesinos, que nem os "ateliers" nem "boulevards" de Paris puderam modificar?

Tempos tão duros atravessa a arte brasileira, que não há, talvez, nesse país cem pessoas que calculem exatamente a extensão da perda que acabamos de sofrer; mas a posteridade fará justiça a Almeida Júnior, e ainda mais sentirá do que deveríamos todos hoje sentir, porque sentirá por nós e por si (“O Paíz”, 15/11/1899, in Almeida, 2007, p . 305).

\section{Referências bibliográficas}

ALMEIDA, Ofélia Fonseca de; AMARAL, Aracy; LOURENÇO, Maria Cecília França; MENDONÇA, Valéria de; SOUZA; Gilda de Mello e; TARASANTCHI, Ruth Sprung. Almeida Júnior: um criador de imaginários. Catálogo da Mostra. São Paulo: Pinacoteca, 2007.

ANDRADE, Mário de, in Grandes Artistas Brasileiros - Almeida Júnior. São Paulo: Círculo do Livro, 1985 (trecho citado sem indicação bibliográfica).

BARDI, Pietro Maria. História da Arte Brasileira. São Paulo: Melhoramentos, 1975.

CARDOSO, Rafael. A Arte Brasileira em 25 Quadros (1790 - 1930). Rio de Janeiro: Record, 2008.

DIAS, Elaine. Almeida Júnior. São Paulo: Folha de São Paulo: Instituto Itaú Cultural, 2013.

MANUEL, Pedro (Supervisor Geral). Arte no Brasil. v2. São Paulo: Abril Cultural, 1979. 
MARTINS, Luis. “Almeida Júnior”. Revista do Arquivo Municipal de São Paulo, Departamento de Cultura, ano VI, v. LXVI, 1940. In Grandes Artistas Brasileiros. Almeida Júnior. São Paulo: Circulo do Livro, 1985.

PALHARES, Taisa (org). Arte Brasileira na Pinacoteca do Estado de São Paulo. São Paulo: Cosac Naify /Pinacoteca/Imprensa Oficial, 2009.

STRICKLAND, Carol. Arte Comparada. Rio de Janeiro: Ediouro, 1999. 